\title{
Repensando a saúde e o tratamento médico
}

Maria Goretti Sales Maciel ${ }^{I}$

“Certas canções que ouço / cabem tão dentro de mim / que perguntar carece / como não fui em quem fiz"

(Milton Nascimento)

$\Lambda$ AO LER $O$ doente imaginado, de MarA co Bobbio, foi essa - da epígrafe - a exata sensação que experimentei. $\mathrm{O}$ médico cardiologista italiano, filho do filósofo Norberto Bobbio (Elogio da serenidade), faz uma reflexão importante sobre a medicina do nosso tempo.

Hora de parar e pensar no que estamos fazendo e a que Senhor estamos servindo. Aonde chegaremos com os paradigmas atuais de uma profissão que, a exemplo de muitas, tropeça entre um passado de poder e uma atualidade de novos poderosos, em que se adequar a pressões tem sido difícil e doloroso?

Seguiremos esses passos sem pensar? Falaremos em nome desses novos senhores? Seremos apenas rebeldes e negaremos a prática assistencial? $\mathrm{Ou}$, de forma responsável, seremos capazes de parar e definir um rumo para a profissão, tendo como principal objetivo a melhoria da vida das pessoas.

Sou uma médica da família, com quinze anos de dedicação exclusiva à prática dos Cuidados Paliativos. Nessa área, é imperioso que todos os dias os paliativistas deparem com esses questionamentos. Cuidar de pessoas com doenças avançadas e por elas fragilizadas não é o mesmo que cuidar de quem goza de melhor saúde e resistência. A perda progressiva da capacidade funcional e o caminho inevitável para a morte tornam o ser humano diferente até de si mesmo em muitos sentidos. Necessitam, portanto, de uma abordagem comple- tamente diferente, individualizada e que contemple os valores da pessoa. Única forma de lhe garantir a necessária dignidade na hora do final da vida.

Pensando e agindo dentro desse novo paradigma, a leitura do livro de Bobbio encontra identificação e exemplos imediatos no dia a dia, não apenas com doentes e instituições, mas com situações vivenciadas por mim mesma e por pessoas muito próximas. Ler $O$ doente imaginado soa como reviver uma cascata de fatos que reforçam e dão ressonância às teses do autor.

\section{Basear um tratamento}

\section{apenas em evidências estatísticas}

Certa vez, aos cinquenta anos de idade e com um incômodo sobrepeso, procurei uma endocrinologista para que orientasse a condução de uma dieta saudável e satisfatória e que olhasse as mudanças hormonais impostas ao meu corpo pela idade. Sem ostentar outros fatores de risco, com dosagem limítrofe de colesterol, HDL acima da média e com hábitos saudáveis como atividade física regular, recebi da jovem médica uma tremenda advertência, um papel impresso com uma dieta genérica que nada tinha a ver como os meus hábitos e uma clara ameaça: se não perdesse peso e não diminuísse a taxa de colesterol no prazo de noventa dias, ela iria me prescrever uma estatina. E arrematou: "E olha que quando prescrevo, é para o resto da sua vida". Saí desolada do consultório. Obviamente dobrei o papel da dieta e decidi 
que iria buscar recursos em outra abordagem, não médica.

Bobbio me ofereceu a certeza de que tinha agido corretamente. A intenção mercadológica de criar novas necessidades, de alterar parâmetros de normalidade, de manipular estatísticas e estudos clínicos em favor da indústria de medicamentos transformou a abordagem de risco no único imperativo médico. Conversar sobre a possibilidade de adotar novos hábitos, pesquisar sobre o meu desejo de usar um medicamento ao longo da vida ou minimamente tentar conhecer minha opinião foram atitudes negligenciadas desde o início da "não relação" estabelecida pela doutora.

\section{Novos diagnósticos \\ e novas necessidades}

$\mathrm{E}$, de repente, o que era saudável até há pouco tempo, virou doença. São vários os exemplos do livro. Assustadora descrição de como, diante da perspectiva de um novo medicamento ou procedimento, toda uma estrutura vai sendo previamente criada para que se crie a necessidade do tratamento.

Lembro de quando uma determinada indústria desejou lançar no Brasil um medicamento injetável, caríssimo em comparação com outras opções terapêuticas vigentes, para reduzir efeitos indesejáveis do tratamento da dor. Fomos convidados a produzir um documento de consenso sobre o sintoma relacionado ao medicamento. Porém, o nome da indústria patrocinadora não deveria aparecer. Mas eles forneceriam toda a estrutura: viagens de experts, os artigos de referência, local e o registro das reuniões e tudo o mais que fosse necessário para a produção do documento.

A participação obviamente foi negada, em nome da entidade que eu dirigia nes- sa época. Ouvi de um jovem associado: "Que vergonha!! Acontecer algo de tão importante para o país e a gente não participar". Não respondi. A resposta se deu pouco depois, quando, diante do óbvio fracasso do medicamento no mercado nacional, a indústria se recolheu e o "importante documento" se apagou junto.

\section{$\mathrm{O}$ adoecimento da vida}

O nascimento, o envelhecimento e a morte são exemplos claros desse outro fenômeno referido no livro. De repente, a pessoa idosa, diante de uma ocorrência clínica tratada de forma desproporcional à sua condição, se vê tremendamente fragilizada por um longo período de internação. Sua recuperação, mesmo que parcial, exige dedicado esforço familiar, acolhimento e um tempo de dependência, variável. Em casa, com esse apoio, muitos se recuperam. Porém, a pressão por sua continuidade nos hospitais ganha, cada vez mais no Brasil, o apoio das autoridades judiciais e a crença de filhos desorientados, segmentados e protegidos que foram do cuidado aos seus avós. Lugar de velho passou a ser o hospital. Até o dia em que os hospitais descobrem que a presença de um doente crônico em seu leito impede de internar um novo doente, apto a receber muitos procedimentos, o que garante o lucro desses verdadeiros shoppings centers da saúde. Aqui, um parêntese: observemos a arquitetura dos grandes hospitais: mármores, grandes fachadas, pé-direito elevado, grandes átrios, lojas, cafés, restaurantes... Com o quê se parecem?

E o nascimento? Por que determinadas fontes financiadoras da saúde privada no Brasil têm a cesariana como 100\% de resultado? O que faz crescer essa cultura?

Médicas jovens e residentes repetem quase como um mantra: "Normal é o 


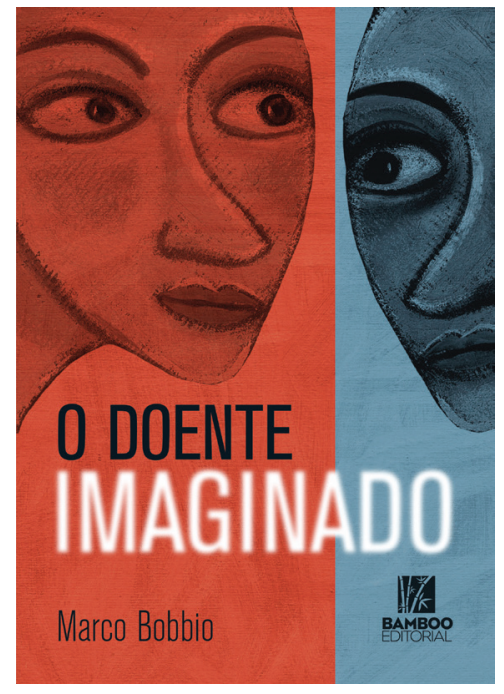

BOBBIO, M. C. O doente imaginado. São Paulo: Bamboo Editorial, 2014. 248p.

parto cesárea”. Certamente um pensamento elaborado por anos de discursos, estatísticas distorcidas e informações cuidadosamente organizadas para que se inverta uma lógica absoluta do corpo humano. E quem ganha com isso? Certamente não é a mulher, cuja vida de novas atribuições deveria the exigir procedimentos que the proporcionem recuperação mais rápida e mais saudável. Muito menos os bebês, que poderiam ser poupados de nascimentos precoces e novas necessidades de medicalização. Mas, certamente, o mercado se beneficia. Minimamente, as maternidades não necessitam destinar leitos de urgência, o número de plantonistas fixos diminui, os médicos podem assumir mais gestantes em seus consultórios porque podem planejar a sua atividade de trabalho.

\section{A morte adoecida}

Esse estranho e sempre presente fenômeno da vida. A morte e o processo do morrer nos proporcionam uma grande reflexão sobre o tema abordado no livro.
Foi na mesma época em que se tornou alvo dos procedimentos tecnológicos que possibilitaram o seu adiamento, que nasceu a discussão e a sistematização de um conhecimento que possibilita esperá-la de forma mais serena e com o menor sofrimento possível: os Cuidados Paliativos.

No entanto, o que predominou nas últimas décadas foi a abordagem mais agressiva do processo de morrer. As Unidades de Tratamento Intensivo se proliferaram. Os protocolos de atenção ao doente crítico ganharam espaço na medicina, em detrimento, muitas vezes, da valorização da vontade da pessoa, dos limites impostos pela sua fragilidade e pela condição de ter uma doença intratável do ponto de vista médico. Mas o contraponto nunca deixou de se manifestar, de tentar demonstrar a importância de distinguir em quem o tratamento agressivo não traria benefício razoável.

O que faltou do lado da Medicina Paliativa, que não conseguiu se impor naquela época? O que prevaleceu na medicina baseada nas grandes intervenções? Quem são seus aliados? E de que forma o ser humano comprou essa ideia da imortalidade, do adiamento da morte a qualquer custo e do pavor da sua chegada. Morte virou sinônimo de fracasso, de impotência, de falência (termo usado coincidentemente para a perda funcional do ser humano). Tudo o que o mercado do valor financeiro abomina. Então, que seja banida também a morte. Que desapareça dos noticiários essa morte que pode nos parecer cotidiana, fisiológica, fruto do adoecimento e do envelhecimento.

O Cuidado Paliativo, não se pode negar, ganha força no mundo. Agora motivado pelas consequências maléficas 
da medicalização da morte. O custo da assistência tornou-se elevadíssimo no último ano de vida, período em o cuidado paliativo pode poupar até $40 \%$ dos gastos com a saúde. Esse custo está levando ao empobrecimento de outras áreas. Então, precisa ser repensado.

A filosofia que norteia o Cuidado Paliativo prega a priorização do indivíduo, visto sempre de forma abrangente e singular. Defende a proporcionalidade e adequação terapêutica em todas as fases do adoecimento e o respeito incondicional à biografia e aos valores do doente, $\mathrm{o}$ qual se torna agente importante em todas as decisões relativas à sua vida.

Esse princípio precisa continuar sendo a grande bússola de toda a prática. Talvez a única forma de não permitir que esse tratamento caia também na banalização e na oferta de serviços baseada nas evidências que interessam apenas ao mercado, em detrimento dos reais interesses de seres humanos.

\section{No final, o que se pode fazer?}

Que atitude assumir? Ignorar a medicina e suas propostas de tratamento soa a individualismo. Negar todo o valor das evidências científicas? Acusar toda pesquisa clínica de manipulação? Fugir de toda e qualquer tentativa de uniformizar tratamentos? Retornar ao empirismo e à medicina baseada apenas na experiência?

Nenhuma saída pode ser individual. O esforço coletivo é imprescindível. É necessário questionar, valorizar o humano e adotar novas posturas.

Significa, em suma, adequar-se ao nosso tempo. Por um lado, sofremos tremendas pressões do mercado da saúde e perdemos o poder da decisão unilateral. Por outro, diante de um paciente mais informado, temos a possibilidade de instigar-lhe a crítica ao mesmo sistema de saúde, que também o coloca em condição de maior vulnerabilidade. Profissionais e doentes devem ser aliados na busca por melhores decisões.

$\mathrm{O}$ que pode fazer da medicina uma prática ajustada ao nosso tempo é o esforço ético de dividir conhecimento, de criar o tempo e as condições adequadas para uma anamnese de valores do doente e ouvir-lhe sempre. São responsabilidades a serem divididas.

O doente, por sua vez, tem que realizar o esforço de conhecer o seu corpo, de observar o que lhe traz ou lhe tira o bem-estar. De buscar informação e ser participativo. Não um rebelde ou mero consumidor, que vai ao shopping center da saúde para consumir a mercadoria cuja aparência mais lhe encantar. Mas um humano atuante, consciente e constantemente transformador. Que reconhece e luta pelos seus direitos.

Certamente, esta reflexão é o grande legado da leitura de $O$ doente imaginado. Tão certo quanto o fato de o livro poder trazer-lhe outras percepções e novas reflexões. Boa leitura!

Maria Goretti Sales Maciel é médica da família e comunidade. Diretora do Serviço de Cuidados Paliativos do Hospital do Servidor Público Estadual de São Paulo (HSPE). @-macielmg@uol.com.br

I Serviço de Cuidados Paliativos, Hospital do Servidor Público Estadual de São Paulo, São Paulo/SP, Brasil. 